\title{
Study on the formation of P orientation in CC Al-Mn-Mg alloy by EBSD method
}

\author{
Q. Zeng and T. Zhai
}

Department of Chemical \& Materials Engineering, University of Kentucky, 177 F Paul Anderson Tower, Lexington, KY 40506

It was reported that the major recrystallization texture of the continuous cast (CC) Al-Mn-Mg alloy sheet was $\mathrm{P}$ orientation $(\{011\}\langle 566\rangle)$ mainly due to the concurrent precipitation effect $[1,2]$. Although efforts have been made to study the formation of the $\mathrm{P}$ orientation, its formation mechanism is not yet fully understood [3]. It is desirable to further understand the formation mechanism of $\mathrm{P}$ orientation in order to control its formation during thermomechanical processing to enhance the formability of CC Al alloys. In this work, the hot band of a commercial CC Al-Mn-Mg alloy sheet $\left(2.54 \mathrm{~mm}\right.$ in thickness) was first annealed at $420{ }^{\circ} \mathrm{C}$ for 3 hours using a heating rate of $15.7 \times 10^{-3}{ }^{\circ} \mathrm{C} / \mathrm{s}$, to the reduce the supersaturation level in the alloy to minimize the concurrent precipitation effect taking place during the subsequent cold rolling (at different reductions) and annealing at $510^{\circ} \mathrm{C}$ for 4 hours. Formation of $\mathrm{P}$ oriented grains in the early stage of recrystallization was then investigated by using EBSD. The chemical composition of the alloy is given in Table.1.

It was found that the $\mathrm{P}$ orientation was the dominant recrystallization texture and that its intensity was strengthened with increase in cold rolling reduction. The volume fraction of the $\mathrm{P}$ orientation was about $30 \%$ at $90 \%$ rolling reduction in the recrystallized sample. The sample with a strong $\mathrm{P}$ orientation was found to have a severely elongated grain structure, the aspect ratio of which increased with increasing cold rolling reduction. The aspect ratio was 10 after $90 \%$ rolling reduction.

To identify the $\mathrm{P}$ oriented grains, orientation maps were obtained by EBSD, in a texture component mode, as shown in Fig. 1(a) where the cube orientation was used as the reference orientation, i.e. cube orientated grain was set to be blue in color (the rainbow bar represents $65^{\circ}$ misorientation). The corresponding $\{111\}$ pole figure of the grains is shown in Fig. 1(b). The P oriented grains in Fig. 1(a) could be identified, as shown in Fig. 2(a) which demonstrates that these P oriented grains are coarse and elongated (over $60 \mu \mathrm{m}$ in length) in the alloy. EBSD orientation mapping of the alloy at the onset of recrystallization revealed that the $\mathrm{P}$ oriented grains were formed by the preferred growth, since they were predominantly coarser and more elongated than those randomly oriented grains in the early stage of recrystallization (Fig. 3(a)). This result indicated that a strong P orientation could be formed in the $\mathrm{CC} \mathrm{Al}$ alloy without the aid of the concurrent precipitation taking place during recrystallization. Densely distributed precipitates (mainly $\mathrm{Al}_{6} \mathrm{Mn}$ ) were observed in this alloy in TEM (Fig. 4). Fig. 4 shows that these precipitates have a strong pinning effect on dislocations. The $\mathrm{P}$ orientation was likely to be formed by these precipitates panning dislocations during annealing. This significantly retarded formation of the commonly appearing texture components, but promoted formation of $\mathrm{P}$ oriented grains, possibly by lattice rotation from the deformed grains in the alloy. Higher the strain (i.e., higher dislocation density), easier the P oriented grains could be formed.

\section{References}

[1] O. Engler, P. Yang, and X. W. Kong, Acta Mater., 44 (1996) 3349.

[2] O. Engler, Mater. Sci. Tech., 12 (1996) 859.

[3] J. T. Liu and J. G. Morris, Metal.1 Mater. Trans. A. 34A (2003) 2029. 

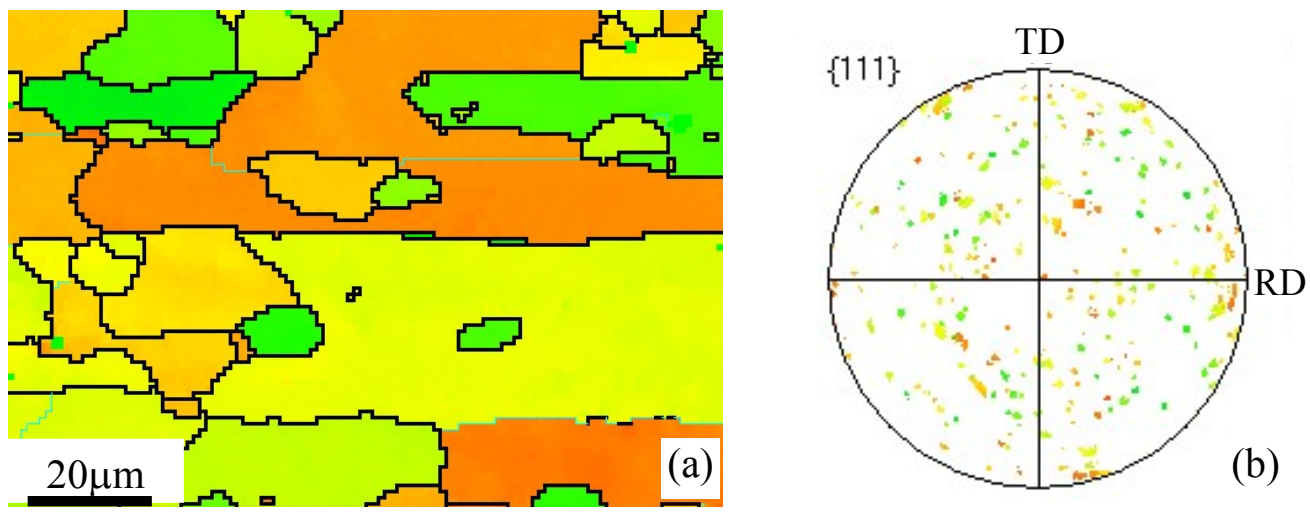

Misorientation

Fig. 1 (a) EBSD map in texture component mode, and (b) the corresponding $\{111\}$ pole figure in a CC Al-Mn-Mg alloy, 85\% rolling reduction.
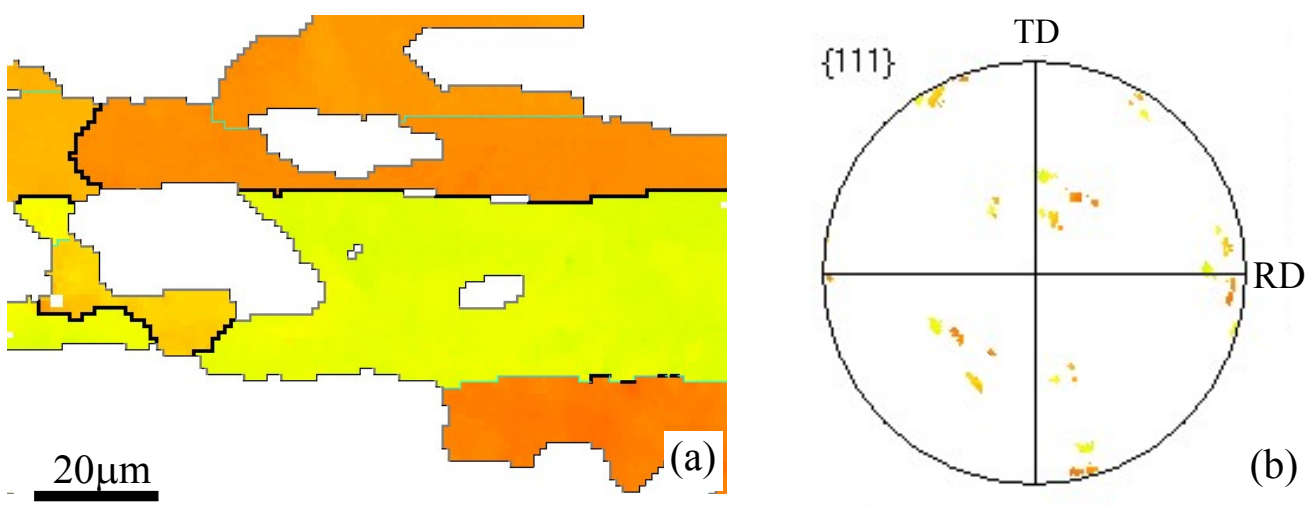

Fig. 2 (a) $\mathrm{P}$ orientated grains in Fig. 1(a) and (b) the corresponding $\{111\}$ pole figure.

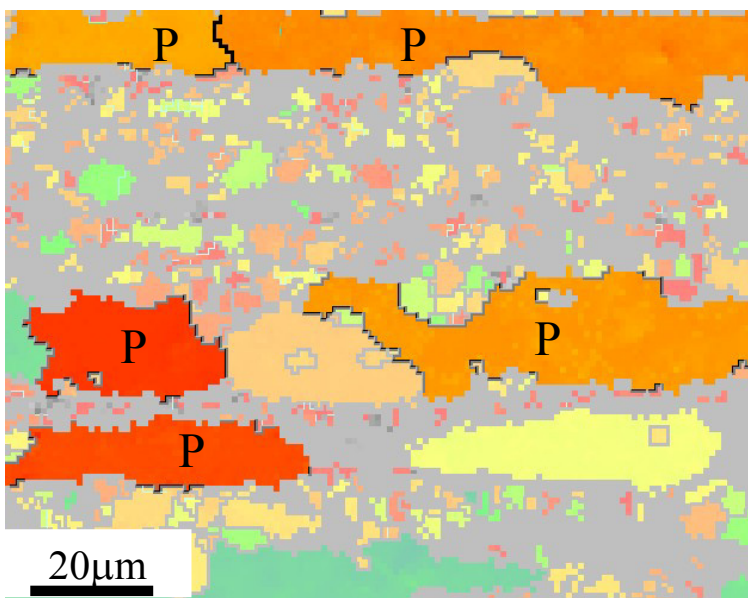

Fig. 3 Preferred growth of the $\mathrm{P}$ oriented grains in the early stage of recrystallization.

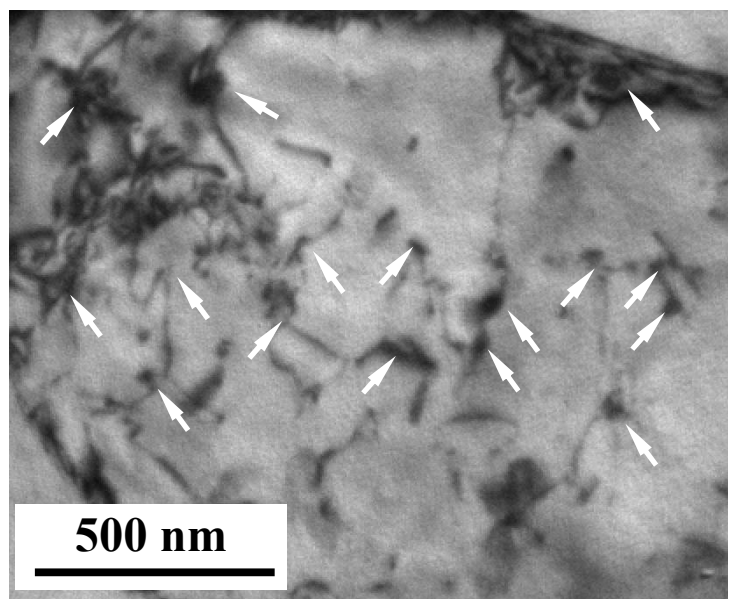

Fig. 4 TEM micrograph showing the pinning effect of precipitates on dislocations

Table1 Chemical composition of CC Al-Mn-Mg alloy

\begin{tabular}{cccccccc}
\hline Alloy & $\mathrm{Si}$ & $\mathrm{Fe}$ & $\mathrm{Cu}$ & $\mathrm{Mn}$ & $\mathrm{Mg}$ & $\mathrm{Zn}$ & $\mathrm{Al}$ \\
\hline $\mathrm{Al}-\mathrm{Mn}-\mathrm{Mg}$ & 0.3 & 0.7 & 0.25 & $1.0-1.5$ & $0.8-1.3$ & 0.25 & $\mathrm{Bal}$. \\
\hline
\end{tabular}

